\title{
DE JOVEM A ESTUDANTE: APONTAMENTOS CRÍTICOS
}

\author{
Samir Pérez Mortada \\ Faculdade Social da Bahia, Salvador, Brasil
}

RESUMO: A partir de memórias e experiências de militantes estudantis atuantes em diferentes épocas, este artigo reflete sobre a transformação do jovem em estudante e sobre o sentido político dessa passagem. Para o tema proposto, foi necessário fazer alguns apontamentos críticos sobre pesquisas atuais acerca da juventude, em especial naquilo que concerne às suas interpretações sobre a participação política dos jovens e às comparações que fazem entre diferentes épocas e contextos da política estudantil. Retomando obra clássica sobre o movimento estudantil, o texto aponta ainda a pertinência e atualidade do pensamento marxista para trazer à tona, em sua integridade, o sentido político da efervescência estudantil dos anos 1960. Para a discussão proposta, foi preciso também pontuar, ainda que de forma breve, transformações no ensino superior brasileiro, metamorfoses que sofreu e sofre no esteio das diferentes imposições do capital.

PALAVRAS-CHAVE: universidade; movimento estudantil; memória.

\section{ON YOUNG ADULTS BECOMING FULL-GROWN STUDENTS: CRITICAL NOTES}

\begin{abstract}
This article comes into being from the memories and experiences of student activists who played key roles at different points in time. It aims to reflect about the transformation of young adults into full-grown students, as well as the political meaning of this passage. In order to approach this theme, it was necessary to make some critical points in regards to current research on youth. These observations specifically focused on the interpretations made by these studies regarding the political involvement of young people as well as comparisons theses studies made between different time frames and contexts of student politics (student activism). By resourcing to a classic masterpiece on student movement, the present discussion points out how pertinent and timely Marxist thought still is. In doing so, it brings into light the political meaning of the student movement effervescence of the 1960's. Furthermore, it was also necessary to succinctly highlight the transformations that took place in Brazil's tertiary education (higher education) along with the metamorphosis it underwent - and still undergoes, as it comes across the impositions brought forth by capitalism.
\end{abstract}

KEYWORDS: university; student polithics; memory.

\section{Apontamentos iniciais sobre o tema}

O que segue originou-se de impasses decorrentes de uma pesquisa em Psicologia Social (Mortada, 2008) inspirada e orientada nos estudos de Ecléa Bosi (1994). Mais especificamente, de um estudo de memória de militantes estudantis atuantes em diferentes épocas no Instituto de Psicologia da USP: décadas de 1960, 1970, 1980 e 1990.

Este artigo procura refletir sobre a transformação do jovem em estudante e sobre o sentido político dessa passagem. Procura fazê-lo através de referência a uma obra inaugural sobre o tema, de comparações temporais baseadas em memórias de militantes estudantis e de apontamentos sobre as mudanças sofridas por esse inusitado agente a partir dos anos 1960 até o presente. Nesse caminho, foi necessário fazer alguns apontamentos críticos sobre produções contemporâneas acerca da participação política juvenil. A partir do contato com militantes de outras épocas, fui levado a retomar, de maneira rápida e instrumental, certas ideias centrais do pensamento marxista. Fui levado também a retomar estudos clássicos que partiam dessa perspectiva. Marialice Foracchi (1977) mostrou-se atualíssima, tanto por suas reflexões sobre a política estudantil como pelo seu método de exposição. A autora constituiu então o principal referencial teórico, e contraponto necessário às pesquisas atuais sobre o tema.

Evidentemente, foi também necessário refletir sobre as transfigurações que sofreu o ensino superior, em estreito compasso com os diferentes momentos do capitalismo em um país periférico. Diferentes configurações produtivas, necessidades de mercado e alternativas nacionais no cenário mundial incidiram e incidem naquilo que se espera da universidade e do estudante, transformando, pela base, o sentido político desses agentes. 


\section{O estudante e a transformação da sociedade brasileira}

A força do movimento estudantil dos anos 1960 fez com que estivesse na berlinda intelectual da época. O Maio de 1968 francês mereceu estudos de nada menos que Alain Touraine, Jean-Paul Sartre, Henri Lefebvre, entre outros. No Brasil, não foi diferente: Octávio Ianni (1968) e Florestan Fernandes (1979) procuraram compreender aquela agitação tão próxima, encabeçada por alunos que encontravam diariamente nos corredores da Faculdade de Filosofia, Letras e Ciências Humanas da USP, no prédio da rua Maria Antonia.

Entre os estudos nacionais, é referência obrigatória a pesquisa de Marialice Foracchi (1977) que dá título a este artigo. $\mathrm{O}$ volume de dados, entre questionários, entrevistas qualitativas e documentos e a qualidade das interpretações revela um esforço acadêmico primoroso, aliado a uma empatia indiscutível da autora com os estudantes. Após mais de quatro décadas, não é por acaso que demonstra maior vitalidade que a maioria das pesquisas contemporâneas sobre juventude e movimento estudantil. Suas hipóteses e conclusões continuam inspiradoras, seja sob o ponto de vista metodológico, seja naquilo em que permanecem atuais.

São abundantes os trabalhos que abordam a singularidade do cenário nacional nesses anos que antecedem e perpassaram a Ditadura Militar. A partir da década de 1930, o Brasil passa por rápidas transformações, saindo de uma estrutura quase exclusivamente rural. Expandemse rapidamente as grandes cidades, tanto sob o ponto de vista econômico como cultural. No cenário internacional, a posição do país parece incerta. A outrora periferia agrária aparentemente poderia galgar um lugar melhor entre as nações centrais. É também um período quente da guerra fria, com movimentos revolucionários bem próximos de nós: outra porta aberta supõe mudanças mais radicais. Possibilidades de reformas sociais profundas estão abertas. Segundo Francisco de Oliveira (2003), naquele período, a mobilização dos trabalhadores poderia efetivamente diminuir a alta exploração da força de trabalho; e a reforma agrária, se realizada, poderia liquidar tanto a fonte fornecedora do exército de reserva de trabalhadores das cidades quanto com o poder das oligarquias rurais.

Os depoimentos de militantes estudantis dos anos 1960 não deixam dúvidas quanto à especificidade desse momento e sobre suas repercussões no engajamento dos jovens. Analisa uma militante: "essa geração foi influenciada pelo nacionalismo romântico, pela ideia de que o país devia inevitavelmente crescer, sair do marasmo anterior, que havia coisas a serem feitas e que isso era também de nossa responsabilidade".

Tais possibilidades e incertezas nacionais permanecem até o recrudescimento da Ditadura Militar, a partir dos anos 1970, quando a modernização conservadora conduzida a partir de então suprime as alternativas nacionalistas ou revolucionárias. Torna homogêneos, se não as vontades, os rumos políticos e econômicos, colocando o país em uma posição periférica e dependente no capitalismo tardio (Oliveira, 2003). Mas temos, até então, um momento em que novas oportunidades parecem tangíveis. Para a classe média, descortinam-se portas de ascensão, entre as quais o ensino superior, antes restrito aos poucos filhos da elite econômica e cultural.

Foracchi interpreta a juventude nesse lugar histórico singular. Sem reduzir os conflitos de gerações a aspectos meramente cronológicos ou naturais, a autora compreende que o jovem torna-se ponto de inflexão de sua classe de origem e de sua própria sociedade. A família é compreendida pela autora como canal de transmissão de pressões mais gerais. Cabe a ela, intuitivamente, fazer com que o jovem cumpra o seu papel. Ou seja, que supere o momento limitado de sua origem social. Formando-se médico, advogado, engenheiro, o jovem perfaz expectativas que $\mathrm{o}$ antecedem e que fazem parte do imaginário de sua família.

A autora faz pormenorizada análise das formas com que essa pressão social-familiar incide nos jovens, especialmente durante a escolha de carreira e a permanência na universidade. Por vezes, trata-se da imposição taxativa de uma carreira. Foracchi encontra entre os estudantes um vasto matiz de graus e tipos variados de autonomia e dependência do jovem em relação à família, desde a imposição taxativa de uma carreira pelos pais até um sentimento difuso de retribuição que os jovens sentem em relação a expectativas e investimentos sobre si.

O que é interessante, nesse momento, é que, paradoxalmente, visando sua ascensão e exercendo seu poder sobre o jovem, a família de classe média propicia a seus filhos possibilidades de rompimento com essa mesma estrutura e destino da qual é representante. É precisamente no momento de escolha profissional, e posteriormente na transformação do jovem em estudante, que Foracchi identifica as possibilidades para a autonomia pessoal e política. Ao ingressarem na universidade, os jovens sofrem uma experiência capaz de ressignificar sua pertença e participação social. Funda-se, no sujeito, uma possibilidade de emancipação que cresce na medida em que ele assume a práxis estudantil, envolvendo-se nas atividades de luta e contestação com seus pares. O estudante, na companhia de outros, goza de uma modalidade de consciência e participação que pode propiciar uma atitude inovadora, crítica sobre seu papel, sua classe de origem e sobre a própria sociedade. O estudante, em relação à sua classe, transforma-se, nas palavras de Foracchi (1977), em ponto de ruptura entre o presente e o passado. Ele seria "o jovem que se nega a si próprio, na medida 
em que age em contradição com todas as determinações sociais do seu comportamento" (p. 115).

Essa dimensão é largamente trazida pelos depoentes que entrevistei. Perguntada sobre seu ingresso no curso de psicologia, uma militante refere-se a um "novo desabrochar", uma continuidade da juventude vivida naquela cujas potencialidades ganham outra dimensão. Destaca a integração entre política e vida cultural, muito presente nos depoimentos da época: "Era tudo junto, não tinha uma separação entre militância política e cultura. Era só a vida que se desabrochava novamente, agora na universidade". A universidade valeu aqui, em sentido arendtiano, como esfera pública, campo político de encontro para o reconhecimento e compartilhamento de anseios, palavras e iniciativas. A força desse lugar não pode ser menosprezada. Sob o ponto de vista individual, Hannah Arendt (2001) refere-se ao ingresso do cidadão na esfera pública como um segundo nascimento. Sobre a força que esse segundo nascimento tem em seus agentes e no coletivo que forma, segundo a autora, altera-se a própria percepção e concretude de nossos anseios, de nossas angústias e inquietações políticas. Em suas palavras, "a presença de outros que veem o que vemos e que ouvem o que ouvimos garante-nos a realidade do mundo e de nós mesmos" (p. 60).

Sugerida a importância emancipadora da transformação do jovem em estudante, cabe a Marialice Foracchi interpretar o movimento estudantil. Novamente, somos remetidos à condição social desses agentes. No trajeto rumo a seu lugar na revolução brasileira, a classe média depara-se com barreiras inesperadas. O ingresso na universidade que vislumbra pela primeira vez em sua história não tem o mesmo glamour: não significa partilhar do mesmo status da classe dominante, tornar-se parte dela, mas compor seu corpo profissional especializado, destinado a exercer as funções que essa lhe destina. Para os estudantes, esse limite aparece quando percebem os obstáculos que enfrentarão para seu estabelecimento profissional. Percebem gradativamente que o sucesso profissional não dependerá apenas de competência ou habilidade, mas das oportunidades e contatos e do capital que dispõem para investir na carreira; percebem que obter uma boa colocação profissional frequentemente demanda realizar atividades que consideram moralmente questionáveis, como competir inescrupulosamente com um colega ou adular um professor; percebem que êxito profissional e valores humanos não convergem; percebem, enfim, ainda que de maneira ingênua, contradições precípuas ao trabalho na sociedade capitalista. Nesse momento, afirma a autora (1977), "esboça-se uma manifestação preliminar da consciência de classe" (p. 204).

Tal descontentamento, segundo Foracchi, é a base para a ampla adesão dos estudantes às lutas pela
Reforma Universitária. Mas a queixa estudantil não se restringe a esse primeiro momento. A pronta e intensa mobilização leva a autora a concluir que, a partir desse solo comum, surgem possibilidades de transcender reivindicações meramente categoriais e ascender a uma crítica mais abrangente. Prova disso é uma das intrigantes características do estudante dos anos 1960: sua adesão radical às lutas das classes proletárias.

Para a autora (Foracchi, 1977), portanto, essa possibilidade revolucionária é dada na própria condição estudantil, na sua capacidade de superar seus horizontes e reivindicações precípuas e reconhecê-las como radicadas em determinações imanentes ao próprio sistema capitalista.

$\mathrm{O}$ aspecto decisivo a considerar é que as reivindicações de carreira levam o estudante a perceber, gradativamente, que as implicações sociais da sua ação são amplas, ou seja, que mais que o padrão vigente de carreira o que ele mais deseja transformar é a ordem que o produz assim. Ou, em outras palavras: o que, na verdade, ele precisa modificar é a ordem social que sustenta esse padrão corrompido de carreira. (p. 201)

Curioso destino: esse pitoresco agente histórico, não tão promissor como o operário do século XIX ou o camponês da revolução maoísta, parece percorrer o caminho traçado por Lenin: vai do espontaneísmo à consciência revolucionária, descobrindo $O$ que fazer a partir das condições que lhe são imanentes.

Assumir a condição de estudante, em si, obviamente não representa disposição revolucionária. Sabese da heterogeneidade de qualquer categoria social, por mais mobilizada e atuante que seja. Marialice Foracchi reconhece esses limites; reconhece suas determinações e vacilações, idas e vindas que não permitem uma definição mais clara na luta revolucionária. Contudo, ainda que pelas ideias e pelo estudo, em um momento curto de inflexão histórica, houve condições propícias para que se formasse uma geração com disposição suficiente para o maio de 1968 francês ou para a luta armada na América Latina.

A radicalidade que Foracchi pesquisou durou pouco: o suficiente para um enigma. É inspirador constatar que o destino desses agentes tangenciou o da classe que mitificavam. Com direito a certo exagero, pode-se dizer que em 1968 o estudante passou de personagem em si a sujeito histórico, para si. Tal como o proletariado que imaginavam, julgaram, com a humildade de quem não se considerava protagonista da revolução, que a transformação de seus destinos seria possível apenas com a transformação do destino de todos.

É importante destacar um ponto central nos trabalhos da autora: a condição de estudante não é tratada como mero subtipo da condição juvenil. Entre o jovem que ingressa na faculdade e o estudante há um percurso 
que, ao mesmo tempo, supera a condição juvenil inicial e a realiza em sua plenitude política. Para a autora (Foracchi, 1972), "enquanto movimento político, radical e ideológico, [o movimento estudantil] é, em contraste, um movimento adulto que contesta em termos adultos, as alternativas propostas pela sociedade" (p. 92). Foracchi vai longe aqui: para ela, portanto, negar a diferença entre jovem e estudante tem caráter ideológico.

Recusar ao jovem a condição de estudante representa negar caráter social às reivindicações dos universitários, equivale a compreender o estudante com base em argumentos que generalizadamente se aplicam ao jovem, tout court: imaturo mas sério, audacioso mas inexperiente, impulsivo mais indeciso. Nessas representações não há distinção entre o jovem e o estudante e, por isso, o caráter estudantil das reivindicações é posto em termos de rebelião, turbulência natural aos que são jovens. (pp. 285-286)

O caráter ideológico dessa operação, no sentido empregado pela autora, seria negar à revolta estudantil caráter social e anticapitalista, atribuindo a ela um sentido natural e cronológico. A anulação da diferença entre jovem e estudante seria reduzir as reivindicações da categoria a instabilidades ou exageros próprios a uma fase cronológica, espécie de etapa em que o descontentamento e a rebeldia são esperados e serão superados na maturidade. Os militantes atuantes durante a campanha pela Anistia lembram bem das cintas da polícia de Erasmo Dias que os perseguiam nas passeatas de 1977. O efeito desse dispositivo era nitidamente rebaixar os manifestantes à condição de filhos rebeldes e sem limites, que precisavam de um corretivo urgente.

\section{Reinvenções da juventude}

Em que pesem a polissemia e as críticas feitas ao termo e ao tema ${ }^{1}$, juventude é campo de estudo bastante atual e valorizado nas ciências humanas. Nos anos 1980, o tom das pesquisas realizadas sobre juventude é geralmente melancólico, especialmente ao analisar o engajamento político dos estudantes em comparação com as gerações precedentes (Medina, 1989). A partir dos anos 1990, a produção acadêmica sobre o tema muda de tom e foco. O movimento estudantil deixa de ser o principal referencial, e são reconhecidas novas formas e espaços de engajamento. O enfoque atual, desde então, é frequentemente marcado por um esforço de ruptura em relação a 1968, pelo combate à sua mitificação e ao peso que esta representa para as novas gerações. Nesse contexto, como referências, destaco os trabalhos de Helena Abramo (1994) e Janice Tirelli Ponte de Sousa (1999):

Desde os anos 80, o movimento estudantil deixou de ser sua principal forma de expressão, o que nos obriga a um olhar mais atento com relação ao novo significado que os jovens procurariam imprimir à sua presença social. Seu ideário parecia desterritorializar-se do espaço tradicional da política para se localizar também em outros espaços, como o dos movimentos populares urbanos. (Sousa, 1999, p. 52)

Analisando as entrevistas que realizou com jovens militantes catarinenses, Sousa (1999) identifica possibilidades de reinvenções da utopia, valorizando a participação e o potencial desses novos agentes: "representam uma parcela de nossa juventude que tem a coragem de se envergonhar diante da violência, da injustiça social, da carência econômica, da discriminação; trazem consigo a capacidade de se mobilizarem e exporem sua indignação" (p. 196). Pesquisas com essa contribuíram decisivamente para desconstruir a falácia de que, ao engajamento heroico dos anos 1960 e 1970, sucederam-se levas de militantes não tão corajosos ou dignos do termo.

Nesse caminho, merece destaque a coletânea de artigos intitulada Retratos da juventude brasileira: análise de uma pesquisa nacional (Abramo \& Branco, 2005), que será tomada aqui como referência central. Diferentes autores, com perspectivas variadas, interpretam dados de pesquisa realizada pela Fundação Perseu Abramo. Destacam-se a heterogeneidade da população jovem, sua distribuição em classes sociais e regiões, o que a torna multifacetada e de difícil enquadramento. A violência, o risco provocado pelas drogas e o desemprego são destacados como grandes temores entre eles. Mas sem dúvida o tema de mais difícil interpretação pelos estudos da coletânea e por outros trabalhos contemporâneos é o da consciência e participação política dos jovens. Nos dados obtidos pela pesquisa, é notável o caráter contraditório das respostas aos questionários aplicados. Receberam altos índices na preferência dos entrevistados valores como solidariedade (55\%), respeito às diferenças $(50 \%)$, igualdade de oportunidades (46\%), justiça social (41\%). Mas os dados também trazem escores significativos de respostas que podem indicar perspectivas conservadoras, tais como a confiança que os jovens depositam na família (98\%), na Igreja Católica $(75 \%)$ e nas Forças Armadas (67\%), consideravelmente maiores que a confiança no movimento sindical $(50 \%)$ ou no movimento Sem-Terra (48\%).

As pesquisas, em geral, observam que, entre os jovens, elementos autoritários e democráticos mesclam-se nas opiniões e comportamentos. Em outra obra recente, Schmidt (2001) afirma tratar-se de uma cultura política híbrida, em que convivem determinações do passado ditatorial, da sociedade capitalista e valores democráticos. Algumas das características contraditórias dessa cultura seriam: apoio difuso e oscilante ao regime democrático; valorização do voto para escolha de governantes; baixa confiança nos agentes e instituições políticas; escolhas eleitorais guiadas por pragmatismo e personalismo; 
valorização difusa da sociedade civil e da participação social em geral; sentimento de impotência na própria capacidade de influir nas decisões políticas.

E se as opiniões dos jovens são de difícil compreensão, pior ainda é entender a passagem das opiniões à participação, da crítica à sociedade e do desejo de transformação à militância. Ou melhor, a ausência dessa passagem. Os dados da Fundação Perseu Abramo demonstram que, embora grande parte dos jovens reconheça a importância de lutar por justiças sociais e pela transformação do mundo, são poucos aqueles que efetivamente se envolvem ou demonstram alguma disponibilidade para a militância. Eis talvez o ponto de maior divergência entre os intérpretes. Muitos autores demonstram perplexidade em identificar esse abismo entre consciência e ação. Afirma Singer (2005):

Em teoria, o mundo padece de violência, miséria, fome, desemprego, uso de drogas etc., e a maioria dos jovens acha que isso deve mudar e que eles, jovens, podem fazer que o mundo mude. Na prática, apenas $2 \%$ estão fazendo e outros $20 \%$ querem fazer que isso aconteça; $68 \%$ nunca pensaram nisso; e $10 \%$ pensaram e desistiram. Por que tantos jovens acham que a juventude pode fazer do mundo algo melhor e tão poucos manifestam a intenção de se engajar em algo que pode ajudar a comunidade? (pp. 34-35)

Procurando respostas à pergunta, Singer (2005) considera dados de pobreza e desemprego sobre a população juvenil, bem como a violência a que estão submetidos. Para o autor, o que a pesquisa indica é que "os jovens brasileiros irão à luta por um Brasil melhor desde que obtenham as bases materiais mínimas de sobrevivência" (p. 35).

Schmidt (2001) também se esforça para compreender o fenômeno da participação política juvenil. O autor procura investigar a socialização política dos jovens brasileiros, entendida como processo de formação de suas atitudes e orientações dirigidas à participação e opiniões concernentes aos assuntos públicos. Esse conceito relaciona-se, na pesquisa, com o de eficácia políti$c a$, que indica a percepção e convicção que o indivíduo tem em relação à sua capacidade de influir no conjunto geral da sociedade. Schmidt aponta escores baixos de eficácia política entre os jovens; reconhece que uma parcela ínfima dos seus entrevistados percebe-se capaz de exercer influência no conjunto geral das instituições políticas, ou de interferir nos grandes problemas sociais como guerras, crimes ecológicos, fome, miséria etc.

Nesse sentido, algumas comparações entre épocas são inevitáveis. Em contraste, a história parecia ao alcance das mãos dos militantes dos anos 1960. Eles lembram o sentimento compartilhado de que havia muito a ser feito no Brasil, e que poderia ser feito. E mesmo nos anos 1970, se não estamos mais na iminência da revolução, se a superioridade bélica e tática das forças conservadoras é incontestável no massacre aos grupos clandestinos, resta na memória dos entrevistados a lembrança da coragem e da solidariedade entre militantes, conscientes de que tinham um papel a cumprir, seja o de preservar o pensamento socialista, seja o de salvar amigos e companheiros. A saída da rua Maria Antonia não foi suficiente para quebrar o laço existente entre os estudantes (Mortada, 2008).

Schmidt aponta ainda que a eficácia política é geralmente proporcional à confiança interpessoal. Afirma que "a rigor, a ausência completa de confiança nos outros impede qualquer ação cooperativa, e inviabiliza as instituições e organizações sociais" (Schmidt, 2001, p. 53). Na memória de militantes dos anos 1970 , se eram pronunciadas e aguerridas as disputas entre as correntes, não foi isso que ficou. Segundo um militante da POLOP, um adversário no movimento estudantil, por mais divergente e combatido, mereceria sempre confiança e respeito; jamais pesariam sobre ele suspeitas de corrupção ou de que traria informações falsas em uma assembleia para obter vantagens no enfrentamento com outros grupos.

$\mathrm{O}$ artigo de Venturi e Bokany (2005) faz contraponto a essas interpretações. Os dados da pesquisa da Fundação Perseu Abramo indicam que a indisponibilidade juvenil para o engajamento é proporcional à registrada em outras faixas etárias. Essa observação é confirmada em outros trabalhos, como o do próprio Schmidt (2001), que nega a tese de uma cultura juvenil específica e apolítica, à parte da adulta. Venturi e Bokany destacam que os jovens do presente são frequentemente comparados com uma expressão da vanguarda juvenil universitária das décadas anteriores. Por vezes, dado o impacto e radicalidade do movimento estudantil das décadas de 1960 e 1970, esquecemos que os estudantes mobilizados correspondiam a uma quantidade inexpressiva da população juvenil nacional.

Há também, nas pesquisas recentes, certa dificuldade em interpretar as novas formas de participação política juvenil. O que parece consensual é que os grupos de jovens são cada vez mais heterogêneos e fragmentados, dedicados a causas mais localizadas: movimentos negros, movimentos de gênero, movimentos ecológicos etc. Tais pesquisas apontam uma militância mais atenta a reivindicações de caráter cotidiano e imediato, distantes das grandes causas revolucionárias. Nas entrevistas com militantes jovens em Santa Catarina, Sousa (1999) observa que suas ações se orientam na direção de uma "transformação social partindo das microrrelações" (p. 181), com vistas a uma utopia que poderá realizarse a longo prazo. Müxel (1997) identifica nos jovens franceses aquilo que chamou de estratégia dos pequenos passos, também deslocada em relação a grandes 
bandeiras e ideários políticos. Outro dado uníssono das pesquisas é o descrédito em relação às instituições tradicionais da política, como partidos políticos, centros acadêmicos, UNE, DCEs, CAs etc. em favor de novas formas de engajamento (Mesquita, 2006).

É forçoso constatar que as pesquisas atuais titubeiam nas tentativas de explicação da participação política juvenil; são menos satisfatórias ainda quando tentam comparar engajamento presente e passado. Os apontamentos, em geral, são parciais e pontuais, em torno de elementos isolados: a situação econômica é distinta; os jovens sofrem da mesma apatia política do conjunto social; carecem de referenciais mais alargados, embora tragam consigo críticas à sociedade e reivindicações de caráter humanista; há, em geral, pouca disposição para o engajamento, mas talvez na mesma proporção que havia no passado... Nesse caminho, estamos à deriva de certo relativismo, uma fragmentação que justapõe partes sem contexto, e por isso rompe com a possibilidade de estabelecer comunicação entre campos de sentido do presente e do passado. O nó se aperta quando procuramos compreender o engajamento estudantil, além de tudo negligenciado pelas pesquisas atuais como se tivesse desaparecido após a década de 1980.

É necessário começar a comparação por um lugar, tanto físico como existencial, e então perfazer um esboço mais estruturado dos agentes do presente e de seu habitat. O eixo de comparação com décadas posteriores deve necessariamente ser o estudante, e para compreendê-lo é imprescindível refletir, ainda que de forma breve, sobre a universidade e suas transformações, pontuando-as em um contexto maior na sociedade capitalista.

\section{O novo mostrengo e seus inabitantes}

É verdade: não nos reconhecemos mais em período tão indefinido como em 1960. À palavra imperialismo nas faixas e dizeres estudantis, veio sua substituta high tech, globalização. No Brasil, do milagre econômico nos anos 1970 vieram a dívida externa, as altas taxas de inflação, o desemprego... Segundo Francisco de Oliveira (2003), a partir dos anos 1980 o potencial de desenvolvimento brasileiro é truncado, e suas alternativas restringem-se no cenário internacional. Analisando a nova fase, o autor aponta o impasse de nossa economia; utilizando sua bem conhecida metáfora zoológica, ratifica: "o ornitorrinco capitalista é uma acumulação truncada e uma sociedade desigualitária sem remissão" (p. 150).

Internamente, configura-se uma sociedade altamente contraditória, porém mais estável e estratificada que décadas atrás. Consolida-se uma classe dominante imersa no hiperconsumo e avessa a ideários nacionalistas. Altos índices de miséria e desemprego convivem com ilhas isoladas de fartura e de alta tecnologia. Em contrapartida, a efervescência do movimento sindical entra em declínio, corroída pela reestruturação produtiva. Segundo Francisco de Oliveira (2003), o ornitorrinco parece não ter perceber muitas alternativas no presente, seja interna ou internamente, seja pela via tucana ou petista.

Chega de retomar mazelas tão bem conhecidas. Só quis ativá-las na memória, como pano de fundo, iniciando um esforço para a compreensão do jovem e de seu (des)engajamento atual. Para o momento, o que importa é notar que, a partir do Golpe de 1964, a universidade foi forçada a enquadrar-se nessa nova ordem pelos técnicos educacionais ligados ao Regime Militar e ao acordo MEC-USAID.

$\mathrm{Na}$ Maria Antonia, durante as mobilizações de estudantes e professores pela Reforma Universitária, Florestan Fernandes (1979) escreveu os trabalhos organizados no livro, cujo nome assertivo e direto não deixa dúvidas sobre a questão colocada: Universidade brasileira: reforma ou revolução? Naquele contexto, os estudantes rebelaram-se contra a universidade conglomerada da década de 1960 descrita pelo autor. O então arremedo de ensino superior não era exemplo a ser seguido; não representava muito além de uma junção fictícia das antigas escolas superiores. Não havia nessa estrutura espaço para pesquisa, produção de conhecimento, e menos ainda para a implicação do pensamento científico com os problemas sociais do país. Segundo o autor, era imperativo transcender os limites de um ensino superior tacanho, herdeiro do atraso cultural português e das elites oligárquicas nacionais. A antiga escola superior destinava-se ao ensino livresco e à reprodução de saberes importados dos centros de excelência estrangeiros; sobretudo, destinava-se à formação de uma elite profissional e intelectual restrita, correspondente a uma ordem econômica prestes a ruir.

Uma depoente lembra a ocupação do prédio da Maria Antonia, da intenção revolucionária dos estudantes frente à escola superior e à universidade conglomerada: "era uma manifestação selvagem. A Maria Antonia viveu o estouro de uma instituição, $e$ as mesmas pessoas que estavam na antiga estavam na nova. Mas ela não nasceu de novo porque foi destruída pela Ditadura".

São muitas referências memorativas sobre esse espaço: seus corredores, o Grêmio, o Bar do Zé... Durante as entrevistas, sonhei com esse lugar, com suas árvores e muros, tamanha a força que as evocações tiveram sobre mim. Sua destruição após a batalha com os estudantes do Mackenzie é emblemática. A eliminação física do prédio simboliza o fim daquele pequeno embrião universitário e o início de um processo de modernização conservadora da instituição: não explodiu como os estudantes pretendiam que explodisse. 
A universidade conglomerada era insuficiente também para o capital. Mas o que surgiu dela foi a universidade burocratizada e funcional dos anos 1970 e 1980. Do ponto de vista do ensino, a expansão de vagas não levou em conta a qualidade, enfraquecendo e desvalorizando a graduação. $\mathrm{O}$ aumento da produção científica foi notável. No entanto, teve seu fluxo e desenvolvimento orientados por padrões norte-americanos, que privilegiam o aspecto quantitativo. As ciências humanas são decisivamente prejudicadas, precisando ajustar-se a normas e padrões vigentes nas áreas exatas e biológicas. Quanto à extensão universitária, carro chefe da proposta progressista, tornou-se o menor dos pilares no tripé institucional. A universidade modernizada, sob o manto da neutralidade, permaneceu alheia aos problemas centrais do país.

Em seguida, nos anos 1990, rapidamente a hegemonia neoliberal impõe novas condições ao ensino superior. Nas universidades públicas, cresce a presença das fundações, bem como a submissão da reflexão autônoma às agências internacionais, como o Banco Mundial, o BID e o FMI. Acentua-se a linguagem gerencial, o referencial externo, a presença e ingerência de organismos internacionais. Vigoram padrões de avaliação característicos de empresas privadas. $\mathrm{Na}$ expressão de Chauí (2001), é a universidade administrada, em que a lógica dos equivalentes mercantis se estabelece na avaliação e comparação entre saberes qualitativamente incomparáveis. A novíssima universidade assemelhase a quaisquer empresas existentes, desde montadoras, lanchonetes ou supermercados.

As propostas inspiradas no Relatório Atcom e nos acordos MEC-USAID sofreram resistências diversas na época, e a implantação de seu conjunto nunca foi completa. Talvez o maior êxito delas tenha se dado de forma temporã, na mentalidade acadêmica a partir dos anos 1990.

$\mathrm{Na}$ expansão avassaladora da rede privada de ensino, as novas instituições são inauguradas sob essa nova doutrina. Como empresas desde o nascimento, são regidas pelas leis da competição e da viabilidade econômica. Os cursos de graduação se orientam para as demandas de mercado; o conhecimento equipara-se à informação técnica mínima necessária para o desempenho profissional. A eficiência, a infraestrutura, a tecnologia e a competitividade são as novas palavras de ordem propagadas pelo marketing agressivo dessas empresas. O que as regulamenta, sobretudo, é o direito do consumidor; é para ele que o estudante vai quando está insatisfeito com o produto adquirido.

Nesse novo quadro, a contrapartida estudantil é desoladora. É triste perceber que são cada vez mais numerosas as entidades discentes que seguem o modelo empresarial. Há associações atléticas, empresas juniores e centros acadêmicos operando com vultosas somas de recursos e frequentemente alheios a quaisquer questões relativas à sociedade brasileira, ou mesmo à melhoria dos seus cursos de graduação. Não raramente surgem rumores ou denúncias comprovadas de corrupção envolvendo seus dirigentes, jovens estudantes que antecipam vícios bem conhecidos do mundo adulto.

Há aqui, nas atléticas e empresas juniores, ainda que reacionárias, algum papel ativo do estudante, um sentimento de pertença e apropriação da faculdade, ainda que de maneira capitalista liberal. Talvez tão ou mais desolador seja perceber que a relação entre a maioria dos jovens com a instituição corresponde efetivamente à estabelecida com um supermercado, lanchonete ou shopping: expressa a passividade de um consumidor, sedado frente à sedução das mercadorias que contempla. Conscientes desse fenômeno, são muitas as instituições privadas que têm em seus campi lojas de roupas, academias, salões de beleza e toda a parafernália necessária para completar o engodo.

E essa objetificação revela-se de maneira especial nos espaços físicos das instituições. Os militantes atuantes no início da década de 1960 recordaram com entusiasmo de seus primeiros anos, da integração entre vida acadêmica, cultura e política. Diz uma depoente: "aquele saguão da Maria Antonia, que perfume, que maravilha. Perfume de vida!". As sínteses sensoriais são recorrentes nos depoimentos da época: "um burburinho, uma efervescência...”. Lembra um militante:

O Bar do Zé era o Prozac da época! Um papo cultural, politico. Era esperar meia hora lá, chegava alguém com quem você tinha algum tipo de afinidade. Acho que era uma vida bem ativa no sentido de conversar: conversava-se... Uma exposição para ir, a casa de alguém... Havia uma continuidade. Acho que era o equivalente ao campus americano, onde há centros de comunidades, onde você encontra seus pares.

O teor das lembranças de lugares muda radicalmente a partir dos anos 1980. Os militantes mais novos ressentem-se de campi semelhantes a tantos outros lugares, igualmente transitórios, igualmente de passagem, embotados para a vida e encontro público. É frequente nos depoimentos dessa época referências a espaços vazios, à necessidade de "integração" com os colegas, como se um sentimento de fragmentação e solidão fosse fortemente experimentado.

No novo mostrengo, a mera presença do aluno tornou-se indesejada, a não ser como consumidor. Esforços na contracorrente dessa tendência encontram obstáculos tanto na terra árida da universidade quanto na disposição dos estudantes em cultivá-la. Assim, na experiência universitária contemporânea, o mero esforço do estudante em habitar sua instituição de ensino, sob qualquer forma ou nível de politização, passa a 
valer como uma espécie de militância, como esforço na contracorrente dessa desertificação. Habitar a universidade passa a ser algo suficiente para distingui-lo de seus colegas que, nas palavras dos depoentes, "assistem as aulas e vão embora".

\section{O estudante em si}

Não é de se estranhar que o estudante dos anos 1960 e 1970 (e em especial sua militância) seja incompreensível aos olhares do presente. Não só pelas transformações na universidade e na vida estudantil, mas também por certos esquecimentos teóricos nas ciências humanas, evidentemente não casuais.

Como observado, as pesquisas recentes frequentemente acentuam nos jovens valores que o sensibilizam para o combate às injustiças sociais, tal como sensibilizavam seus antecessores; afirmam, a partir daí, que a práxis juvenil deve ser compreendida em seu novo contexto socioeconômico, que ela não seria nem melhor nem pior que o engajamento pregresso, mas produto do que é hoje possível realizar, daí sua diversidade e heterogeneidade. Nas pesquisas recentes, os elementos isolados da militância juvenil são comparados a características também isoladas da militância pregressa. Esses estudos creem, assim, avançar ao não menosprezar os agentes do presente e não mitificarem os agentes do passado. Contudo, na repulsa à força mítica de 1968 suprimiu-se seu caráter singular, seu contexto íntegro e existencial e, portanto, aquilo que poderia servir como potencial crítico, renovador para as gerações futuras.

Franklin Leopoldo e Silva (1988) observou décadas atrás essa dificuldade em interpretar a "Maria Antonia". Nenhuma explicação isolada sobre conjunturas políticas, valores em transformação, aspectos existenciais, embora possa ser precisa sobre determinados aspectos particulares, pode dar conta do entrelaçamento complexo entre elas. Cada elemento da vida universitária, comparado ao seu correlato de outra época, dá impressões falseadas. Justapondo a política do passado à do presente, as músicas do passado às do presente, a literatura do passado à do presente, obtemos diferenças circunscritas, indicações parciais que podem obscurecer aquilo que é essencial. A tendência para que procedamos de maneira partitiva com o passado é claramente determinada pelo nosso presente, pelo esvaziamento e compartimentalização de nossas consciências frente a um mundo de aparência caótica.

Vale lembrar estudos atuais menos partitivos. Já na década de 1980 era possível estabelecer interpretações mais integradas sobre a nova condição dos estudantes. Em texto simples e certeiro, creio que inspirado em algum engajamento estudantil anterior, Ribeiro Neto (1985) é talvez o primeiro a apontar com essa assertividade que a condição de estudantes deixa de exercer papel central na vida dos jovens: "deixa de significar um investimento global, um território onde múltiplas experiências podem encontrar-se e ser pensadas" (p. 63). Nos anos 2000, Luís Antonio Groppo (2005) procurou identificar pontos de convergência e divergência nos diferentes países em que houve intensa mobilização estudantil em 1968. Destaca o contexto de guerra fria, aspectos econômicos, políticos e culturais de uma sociedade global em expansão. Nesse momento, a transformação do sistema universitário também aparece como um aspecto comum entre diversos países. Segundo o autor, a mobilização dos jovens nas décadas de 1960 e 1970 deitou raízes em expectativas alargadas em comparação com as do presente, alcançando expressão mundial. Conclui Groppo que a onda mundial de revoltas de 1968 foi o primeiro grande movimento por uma outra globalização, e que esta talvez seja sua principal herança para as novas gerações.

Esses trabalhos são exceções. Em verdade, hoje, é cada vez mais difícil compreender tanto os acontecimentos de 1968 como o estudante por limitações do próprio presente, e nos serve de pista, um tanto irônica, precisarmos resgatar uma pesquisa da década de 1960 para compreendermos o sentido político desse problema. Como vimos, para Foracchi, o processo de transformação do jovem em estudante possui determinações históricas complexas, e deve ser interpretado em seu sentido mais alargado. A análise feita pela autora é evidentemente inspirada nas discussões sobre o problema da organização do proletariado, nas divisões possíveis de um movimento, na articulação entre sua base e seus militantes. É clara a presença, ainda que nem sempre explicitada em seu texto, dos conceitos de classes sociais e de consciência de classe; para interpretar a passagem de um movimento estudantil espontaneísta e sindical para outro, que leva em conta determinações mais gerais do sistema capitalista.

O conceito de classes sociais, a temática da consciência de classe e da passagem da classe em si à classe para si constituem campo complexo e atravessado por ricas e variadas perspectivas. Aqui, não há consenso mesmo entre os autores marxistas, e tampouco definição inequívoca e precisa na própria obra de Marx $^{1}$. Não é necessário entrar nesse debate. O que importa, no momento, é aquilo que, pela problemática que coloca e procura enfrentar (as questões de organização do proletariado), esse conjunto de expressões nos permitiu, ainda que de maneira apenas esboçada ou subentendida na obra de Foracchi, desvelar acerca do movimento estudantil e de certas dificuldades das pesquisas contemporâneas sobre a participação política dos jovens.

O que chama também especial atenção no trabalho de Foracchi é a forma de exposição e de integração 
dos elementos revelados pelos dados da pesquisa. Essa é sua pedra de toque. Para Lukács (2003), o método marxista distingue-se pela perspectiva da totalidade, única capaz de superar a imediaticidade e superficialidade com que o real se apresenta. Sob essa perspectiva, o conhecimento do real é possível apenas pelo esforço de integração dos diferentes fatos da vida social. Embora a construção do conhecimento deva necessariamente partir daquilo que é imediato à percepção e ao pensamento, é necessário que rompa tal superfície. O conceito de totalidade, metodologicamente, indica que o foco de estudo, apesar do recorte que se faz a partir da perspectiva de pesquisa, não é tratado em isolamento ou decomposto em partes, mas concebido historicamente e indissociável do mundo que o cerca.

Foracchi alcança estabelecer um campo de sentido no qual categorias de análise e dados empíricos não aparecem de maneira estanque e compartimentada; suas interpretações estabelecem relações e impostações cada vez mais alargadas, relacionando categorias simples e abstratas à complexidade e concretude do tema. A autora não perde de vista determinações sociais mais amplas ao interpretar os jovens e os estudantes, sem suprimir particularidades, nem tampouco equipará-las a estas na forma de exposição e em suas conclusões. Daí a inegável superioridade de seu trabalho em relação aos seus sucessores, apesar dos quarenta anos que o separam de nós. Embora haja o benefício de encontrarmos informações atualizadas nas pesquisas mais recentes, somos obrigados a reconhecer que um trabalho à altura de servir como via de comparação com o realizado outrora deveria necessariamente retomar certas categorias e esforços metodológicos hoje esquecidos.

Portanto, a equiparação entre jovens e estudantes nas pesquisas atuais, que tomei como ponto de partida deste artigo, indica, sob o prisma metodológico, antinomias das pesquisas sociais contemporâneas que pareceriam claras décadas atrás, ainda nos anos 1980. Outra triste revelação, sem dúvida decorrente em grande parte da primeira, é a dificuldade que temos, nós pesquisadores, de perceber os desdobramentos de uma vida acadêmica desertificada. Bastaria que as pesquisas mais recentes partissem desse lugar, desse mesmo lugar que habitam seus próprios pesquisadores, e refletissem em um primeiro momento sobre seu local de trabalho. De fato, hoje, tem cada vez menos sentido conceber a universidade como experiência decisiva para um jovem, como momento de pertença e politização para quaisquer de seus habitantes. E se essa dificuldade figura com tanta força nas pesquisas, a ponto de elas ignorarem ou diminuírem a importância da transformação do jovem em estudante, é porque o monstrengo nos absorveu de tal forma que somos cada vez menos capazes de colocarmos o pescoço para fora de sua garganta e olharmos para trás.
Decênio a decênio, não é sem motivos que os acontecimentos de 1968 ficam cada vez menos compreensíveis para os habitantes da universidade, e isso não se dá evidentemente porque eles ficaram mais afastados de nós; mas porque, década a década, nosso olhar e nosso lugar - este em sentido estrito: a universidade -, do qual necessariamente deveria partir a reflexão sobre 1968, passou a ser a sua própria negação. A universidade, a não ser nos momentos de greve e mobilização, não comporta mais a vida íntegra e politizadora de antes, não vai além do que lhe pede o capital e lhe permite sua burocracia. Nada mais próximo daquilo que as mobilizações pela Reforma Universitária combatiam.

\section{Notas}

1 Sobre essa polêmica, ver Bourdieu (1983) e Dubet (1996). Sobre as dificuldades em definir juventude, ver Abramo e Branco (2005) e também Levi e Schmidt (1996).

2 Entre outros títulos, ver Bottomore (1968), Lukács (2003) e Thompson (1987). Para uma referência rápida, ver Bottomore (1988).

\section{Referências bibliográficas}

Abramo, H. W. (1994). Cenas Juvenis: punks e darks no espetáculo urbano. São Paulo: Scritta.

Abramo, H. W. \& Branco, P. P. M. (Orgs.). (2005). Retratos da juventude brasileira: análises de uma pesquisa nacional. São Paulo: Fundação Perseu Abramo.

Arendt, H. (2001). A condição humana. Rio de Janeiro: Forenseuniversitária.

Bourdieu, P. (1983). Ajuventude é apenas uma palavra. In Questões de sociologia (pp. 112-121). Rio de Janeiro: Marco Zero.

Bosi, E. (1994). Memória e sociedade: lembranças de velhos. São Paulo: Companhia das Letras.

Bottomore, T. (1968). As classes sociais na sociedade moderna. Rio de Janeiro: Jorge Zahar Editor.

Bottomore, T.. (1988). Dicionário do pensamento marxista. Rio de Janeiro: Jorge Zahar Editor.

Cardoso, I. (2001). Para uma crítica do presente. São Paulo: Editora 34.

Chauí, M. (2001). Escritos sobre a universidade. São Paulo: Editora UNESP.

Costa, J. F. (2003). Violência e psicanálise. Rio de Janeiro: Graal.

Dubet, F. (1996). Les jeunes et des sociologies: le cas français. Sociologie et sociétés, 1(28), 23-35.

Fernandes, F. (1979). Universidade brasileira: reforma ou revolução? São Paulo: Alfa-Ômega.

Foracchi, M. M. (1972). A juventude na sociedade moderna. São Paulo: EDUSP.

Foracchi, M. M. (1977). O estudante e a transformação da sociedade brasileira. São Paulo: Editora Nacional.

Groppo, L. A. (2005). Uma onda mundial de revoltas: movimentos estudantis de 1968. Piracicaba: Editora UNIMEP.

Ianni, O. (1968). O jovem radical. In S. Britto (Org.), Sociologia da juventude (Vol. 1, pp. 225-242). São Paulo: Zahar.

Krischke, P. J. (2005). Questões sobre juventude, cultura política e participação democrática. In H. W. Abramo \& P. P. M. 
Branco (Orgs.), Retratos da juventude brasileira: análises de uma pesquisa nacional (pp. 323-350). São Paulo: Fundação Perseu Abramo.

Levi, G. \& Schmidt, J-C. (1996). História dos jovens. São Paulo: Companhia das Letras.

Lukács, G. (2003). História e consciência de classe: estudos de dialética marxista. São Paulo: Martins Fontes.

Medina, C. (Org.). (1989). 1968-1988: Nos passos da rebeldia. São Paulo: CJE/ECA/USP.

Mesquita, M. R. (2006). Identidade, cultura e politica: os movimentos estudantis na contemporaneidade. Tese de Doutorado em Psicologia, Pontifícia Universidade de São Paulo, São Paulo.

Mische, A. (1997). De estudantes a cidadãos: redes de jovens e participação política. Revista Brasileira de Educação, 5/6, 134-150.

Mortada, S. P. (2008). Tempos da politica: memórias de militantes estudantis do curso de psicologia da Universidade de São Paulo. Tese de Doutorado em Psicologia, Universidade de São Paulo, São Paulo.

Müxel, A. (1997). Jovens dos anos noventa: à procura de uma política sem "rótulos". Revista Brasileira de Educação, 5/6, 151-166.

Oliveira, F. (2003). Crítica à razão dualista - O ornitorrinco. São Paulo: Boitempo.

Ribeiro Neto, A. (1985). Um laço que não une mais. Desvios, 4, 58-71.

Schmidt, J. P. (2001). Juventude e política no Brasil: a socialização política dos jovens na virada do milênio. Santa Cruz do Sul: EDUNISC.

Silva, F. L. (1988). Rua Maria Antonia. In: M. C. L. Santos (Org.), Maria Antonia: uma rua na contramão (pp. 132-136). São Paulo: Nobel.
Singer, P. (2005). A juventude como coorte: uma geração em tempos de crise social. In H. W. Abramo \& P. P. M. Branco (Orgs.), Retratos da juventude brasileira: análises de uma pesquisa nacional (pp. 27-35). São Paulo: Fundação Perseu Abramo.

Sousa, J. T. P. (1999). Reinvenções da utopia: a militância política de jovens nos anos 90. São Paulo: Hacker Editores.

Thompson, E. P. (1987). A formação da classe operária inglesa. Rio de Janeiro: Paz e Terra.

Venturi, G. \& Bokany, V. (2005). Maiorias adaptadas, minorias progressistas. In H. W. Abramo \& P. P. M. Branco (Orgs.), Retratos da juventude brasileira: análises de uma pesquisa nacional (pp. 351-368). São Paulo: Fundação Perseu Abramo.

Samir Pérez Mortada é Doutor em Psicologia Social pelo Departamento de Psicologia Social e do Trabalho do Instituto de Psicologia da Universidade de São Paulo. Professor de Psicologia Social na Faculdade Social da Bahia - Salvador, colaborador do Centro de Memória do Instituto de Psicologia da Universidade de São Paulo. Endereço para correspondência: Rua Amazonas, 845 apto. 03. Salvador - BA. CEP: 41830-380. E-mail:mortada@usp.br.

De jovem a estudante: apontamentos críticos

Samir Pérez Mortada

Recebido em: 08/08/2008

Revisão em: 16/09/2009

Aceite final em: 26/10/2009 